04

\title{
Исследование динамики формирования плазмоидов в гатчинском разряде
}

\author{
(c) Shixin Zhao, ${ }^{1}$ Chengxun Yuan, ${ }^{1}$ A.A. Кудрявцев, ${ }^{1,2}$ О.М. Жеребцов, ${ }^{3}$ Г.Д. Шабанов ${ }^{1,3}$ \\ ${ }^{1}$ Department of Physics, Harbin Institute of Technology, \\ 150001 Harbin, China \\ ${ }^{2}$ Санкт-Петербургский государственный университет, \\ 199034 Санкт-Петербург, Россия \\ ${ }^{3}$ Петербургский институт ядерной физики им. Б.П. Константинова Национального исследовательского центра \\ „Курчатовский институт“, \\ 188300 Гатчина, Ленинградская обл., Россия \\ e-mail: shabanov_gd@pnpi.nrcki.ru
}

Поступило в Редакцию 11 декабря 2020 г.

В окончательной редакции 27 января 2021 г.

Принято к публикации 27 января 2021 г.

\begin{abstract}
Представлены результаты исследований гатчинского разряда, проведенных в Харбинском технологическом университете (Китай). Гатчинский разряд используется в основном для создания аналога шаровой молнии в обычной атмосфере лаборатории. Большая часть исследований этого разряда различными группами ученых посвящены изучению первой фазы разряда, когда электрический разряд имеет гальваническую связь с электродом. Это связано с тем, что многие исследователи считают эту фазу разряда определяющей для последующего длительного существования автономного светящегося образования - второй фазы разряда. В работе по сравнению с аналогичными работами более полно и с лучшим разрешением продемонстрирован лидерно-стримерной процесс, происходящий на поверхности воды. Применение фильтра позволило полнее показать роль лидеров, стримеров и области ионизации в непосредственной близости у поверхности воды и уточнить некоторые процессы, происходящие в автономной фазе разряда. В диапазоне длин волн $400-500 \mathrm{~nm}$ светящееся образование в автономном режиме показало более длительное время существования в виде шарообразной формы, чем при наблюдении в „белом“ свете. При резком увеличении количества вносимого вещества на катод зарегистрирован новый физический эффект, который заключается в том, что в среде обычной атмосферы образуется, не теряя контакта с электродом (катодом), сложноустроенное образование белого цвета. Варьируя электропроводность и начальное напряжение, впервые получено неожиданно маленькое светящееся образование диаметром 15-17 mm, которое ранее в гатчинском разряде не наблюдалось.
\end{abstract}

Ключевые слова: гатчинский разряд, плазмоид, долгоживущие светящиеся образования, плазменный лист, пространственный заряд, виртуальный катод, шаровая молния.

DOI: 10.21883/JTF.2021.07.50952.342-20

\section{Введение}

В 2000 г. был открыт новый вид электрического разряда при атмосферном давлении в Петербургском институте ядерной физики, находящегося в г. Гатчина [1]. По названию города он получил название „гатчинский разряд“. В гатчинском разряде образуются уникально долгоживущие светящиеся образования, которые, по мнению авторов и многих других исследователей, поразительно похожи на природные шаровые молнии и в связи с этим этот разряд оказался интересным для многих лабораторий мира [2]. Несмотря на исследование гатчинского разряда в течение 20 лет, единого мнения о его природе нет.

Гатчинский разряд представляет собой импульсный электрический разряд с поверхности воды в воздушное полупространство. В данном разряде формируются долгоживущие светящиеся образования (плазмоиды ${ }^{1}$ ), о структуре которых имеются различные мнения (см., например, [3-10] и разд. 7). Наиболее полно гатчинский разряд описан в работе [2]. Для рождения плазмоидов используется конденсаторная батарея емкостью $0.6 \mathrm{mF}$ заряжаемая до $5.5-6.0 \mathrm{kV}$. С батареи два электрода заведены в полиэтиленовую емкость диаметром $8 \mathrm{~cm}$, наполненную водой. Разряд инициируется с графитового электрода, который находится в центре полиэтиленовой емкости. Электрод имеет диаметр $6 \mathrm{~mm}$ и выступает над поверхностью воды на высоту $2-3 \mathrm{~mm}$. Боковые поверхности электрода изолированы от воды кварцевой трубкой. Кольцевой электрод противоположной полярности

\footnotetext{
1 Далее в настоящей работе будет использоваться термин „плазмоид“. Мы считаем, что этот термин не отражает физической сути образующегося в разряде долгоживущего светящегося образования, но он удобнее (как более короткий) и к тому же используется основной массой исследователей.
} 

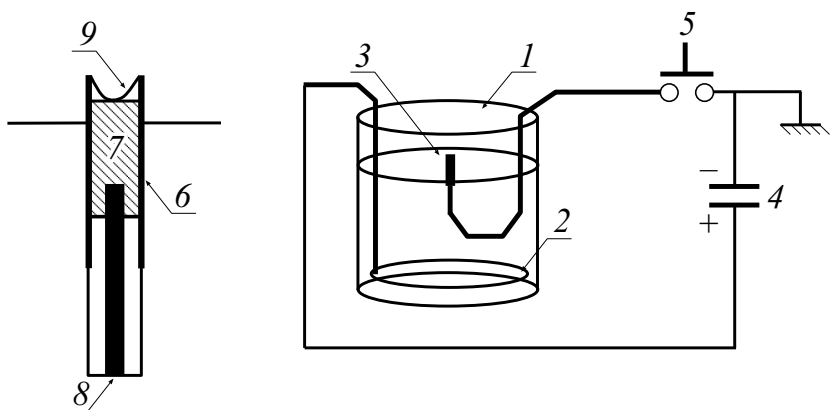

Рис. 1. Установка для получения долгоживущих светящихся образований: 1 - полиэтиленовая емкость, $2-$ кольцевой электрод, 3 - центральный электрод (катод), 4 - конденсаторная батарея емкостью $0.6 \mathrm{mF}, 5-$ разрядник, 6 - кварцевая трубка, 7 - угольный или металлический электрод, 8 - медная шина, 9 - капля воды или вещества вводимого в разряд.

(анод) находится в воде на глубине $15 \mathrm{~cm}$ (рис. 1). После подключения конденсаторной батареи к разрядному промежутку на поверхности воды образуется плазменный лист, и с электрода, расположенного над водой, появляется струя направленная вверх. На 80-ой ms разрядник размыкается (остаточное напряжение $\approx 3 \mathrm{kV}$ ) и струя, оторвавшись от электрода, формируется в плазмоид [2]. При образовании плазмоида в разряде можно выделить две фазы его формирования. В первой фазе разряда на поверхности воды начинает формироваться плазмоид, и разряд гальванически связан с источником питания. В это время у катода плазменный лист начинает подниматься вверх, из которого формируется будущая оболочка плазмоида. Во второй фазе разряда плазмоид гальванически не связан с источником питания и светится за счет запасенной в первой фазе разряда энергией. Почти все исследователи, например $[3,5,6,8,10]$ считают, что первая фаза разряда является самой важной для последующей „жизни“ автономного плазмоида, и эта фаза определяет время продолжительности его свечения.

Первыми получили фотографии первой фазы разряда с лидерно-стримерной „паутиной“, исходящей от катода, авторы работы [3]. На фотографиях из их работы видно, что в начале первой фазы лидерно-стримерная паутина „лежит“ на воде. Лидеры исходят из ярко светящейся области у электрода. В своем развитии у разряда, во второй половине первой фазы, ярко светящаяся область у электрода поднимается вверх, и выходящие лидеры из этой светящейся области поднимаются вместе с ней над водой, причем концы лидеров со стримерной короной не теряют контакта с водой. Все это становится похожим на паучка, стоящего на лапках. В [3] предположили, что именно в этот момент первой фазы образуются высокоэнергетические ионы и атомы, которые поступают в плазмоид и определяют длительность второй фазы, когда плазмоид не имеет гальванической связи с электродом и существует только за счет запасенной энергии $[3,6]$. Гатчинский разряд первые десятки ms имеет сильную светимость. При сильном диафрагмировании удается получить достаточно хорошие фотографии, например [3,8]. Мы считаем, что существует методически неправильная интерпретация гатчинского разряда при анализе экспериментальных данных. Эта интерпретация связана большей частью с кадрами из видеоматериалов, полученных в белом свете. Но в „белом свете“, учитывая диаграмму видности, оптическое смешение цветов, мы понимаем, что часть информации теряется [1]. Получение утерянной информации возможно, в частности, при применении светофильтров (светофильтр в оптике, технике - оптическое устройство, которое служит для подавления (выделения) части спектра электромагнитного излучения). Узкополосный светофильтр будет способствовать выделению части спектра с предполагаемыми процессами, которые обнаруживают себя в определенном частотном диапазоне спектра с локализацией места излучения (что труднодостижимо при использовании спектрографов) в плазмоиде. Приведенные ниже эксперименты показали плодотворность данного подхода.

Основной целью настоящей работы было:

1. Поиск способов исследования первой фазы разряда путем варьирования как режимов разряда, так и способов его регистрации.

2. Кроме этого, в настоящей работе удалось в пространстве над электродом (катодом) изменить конфигурацию и механизм функционирования первой фазы разряда. Это позволило наблюдать новый физический эффект - формирование в среде обычной атмосферы сложноустроенного образования белого цвета, имеющего контакт с электродом (катодом).

3. При поиске диапазона напряжений, в котором возможно образование плазмоидов в гатчинском разряде, неожиданно получен уникально маленький по размерам плазмоид, образование которого схоже с образованием шаровых молний на проводниках.

\section{1. Схема установки, видеосъемка разряда}

Схема установки гатчинского разряда с указанием основных ее элементов приведена на рис. 1. Выше описаны фазы разряда в процессе его развития.

В начале экспериментальной работы для „калибровки“ установки были получены стандартные плазмоиды без добавок (рис. 2,a) и с добавкой на катод коллоидного графита (рис. 2,b). На рис. 2, $a$ приведен эксперимент: файл № 226, диаметр плазмоида $\approx 15 \mathrm{~cm}$, свечение в автономной фазе $\approx 400 \mathrm{~ms}$ (этот и все последующие эксперименты проводил Shixin Zhao). В следующем эксперименте на катод добавили коллоидный графит (файл № 1248 (рис. 2,b)), у плазмоида появился ореол красного цвета, диаметр увеличился до $\approx 17 \mathrm{~cm}$, но время свечения в автономной фазе сократилось до $\approx 360 \mathrm{~ms}$. 


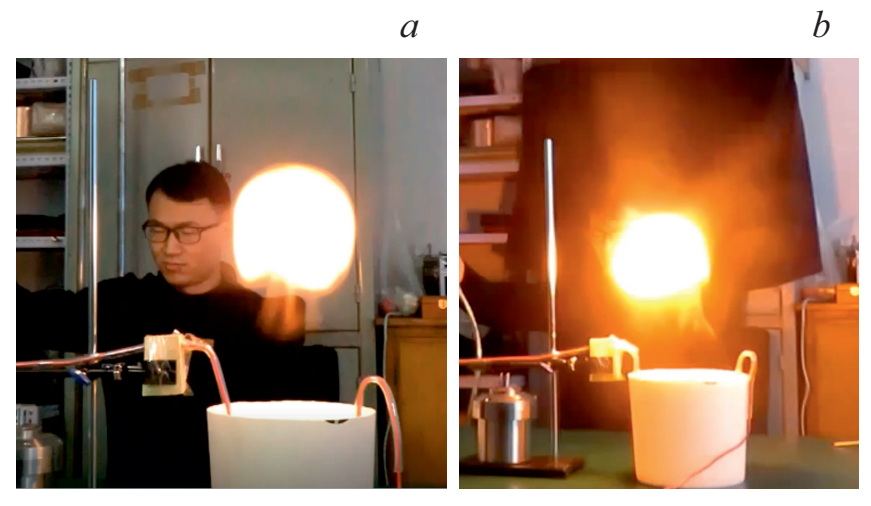

Pис. 2. Съемка в лаборатории при нормальном освещении: $a-$ плазмоид без добавок, $b-$ в плазмоид введен коллоидный графит.

Свечение в автономной фазе, как правило, наиболее обсуждаемый параметр при рассмотрении свойств плазмоидов. Максимальное время существования гатчинских плазмоидов, полученных на установке, собранной для настоящей работы, составляет около $600 \mathrm{~ms}$ (в автономной фазе до $500 \mathrm{~ms})$. В настоящей работе наблюдаемые времена свечения плазмоидов несколько ниже возможной (до $1 \mathrm{~s})$, полученной в традиционной схеме установки с заземленным анодом [2]. Изменение электрической схемы было связано с тем обстоятельством, что в распоряжении коллектива настоящей работы использовался источник высокого напряжения с заземленным катодом. Также отметим, что вопросы сравнения объектов (в том числе и времен свечения), полученных в гатчинском разряде, с объектами, наблюдаемыми при других способах инициирования, и с шаровой молнией, вынесены в разд. 7 настоящей работы.

\section{2. Воспроизведение лидерно-стримерной „паутины “}

На первом этапе были выполнены эксперименты, в которых удалось улучшить результаты работ $[3,8]$. Разряд в работе [3] с начала первой фазы до окончания свечения существовал менее $200 \mathrm{~ms}$, а в [8] снимок сделан со временем экспозиции $1.25 \mathrm{~ms}$ в период времени от 17 до $33 \mathrm{~ms}$ после подачи энергии на электроды. То есть в первом случае была, в частности, мала мощность разряда, что могло скрыть важные детали развития разряда, а во втором случае недостаточное временное разрешение кадров. Мы поддерживаем мнение авторов [8], которые считают, что начальная фаза, т. е. образование плазменного шара в течение времени, когда на электроды подается напряжение, представляет особый интерес для идентификации каналов подачи энергии. Также представляет интерес замечание в [8] о том, что стримеры возбуждают водяные волны из-за локального и быстрого повышения температуры и что должна быть видна интерференция. Поэтому основная часть нашей работы была посвящена исследованию первой фазы разряда.

В первых экспериментах был получен стандартный „паук“ из расходящихся от электрода лидеров. На рис. 3 приведены кадры из видео № CO127.MP4 снятой камерой Sony FDR-AX700, 500 fps. Коммутация разряда происходила при напряжении на конденсаторной батареe $5.50 \mathrm{kV}$, а при $2.37 \mathrm{kV}$ разряд прерывался. Свет от разряда появляется на первом кадре в диапазоне от 0 до $2 \mathrm{~ms}$ и в это время лидеры имеют длину около $6 \mathrm{~cm}$ (рис. $3, a)$. На втором кадре (рис. $3, b$ ), экспонирование происходит в диапазоне от 2 до $4 \mathrm{~ms}$ и лидеры имеют длину немногим более $9 \mathrm{~cm}$, видны зарождающиеся на воде волны, расходящиеся от растущих лидеров. Разрешение на кадрах видео достаточное для регистрации пульсирующего образования волн, которые в каждый момент времени более интенсивны у основания „паука“ и только зарождаются на концах растущих лидеров. На рис. $3, d-18 \mathrm{~ms}$, волны начинают взаимодействовать друг с другом, создавая интерференционную картину. Лидеры достигают своей наибольшей длины (около $11 \mathrm{~cm}$ ), но их очертания становятся все более размытыми. Все это время светящееся ядро поднимается вверх и на рис. $3, e, f$ видим, что лидеры исходят не из центрального электрода, а из плазменного шарика (по терминологии $[8]$ ), находящегося над электродом. Вследствие этого вблизи электрода лидеры отрываются от воды. Чем больше времени проходит от начала разряда, тем большая часть каждого лидера оказывается оторванной от поверхности воды. Весь разряд постепенно поднимается вверх и все больше похож на паука, стоящего на лапках на поверхности воды.

На кадрах 44 (рис. $3, e$ ) и $54 \mathrm{~ms}$ (рис. $3, f$ ) видно, что лидеры начинаются высоко над электродом (на высоте 5-6cm), спускаются вниз к воде, и стоят на концах лидеров со стримерной короной $[11,12]$. Их длина проекции на радиальное направление существенно сокращается. Волны на воде, образованные лидерами, продолжают интерферировать. На последних кадрах 66 (рис. $3, g$ ), $78 \mathrm{~ms}$ (рис. $3, h$ ) первая фаза разряда практически закончилась и, оторвавшись от воды и электрода, плазмоид начинает свое автономное существование.

\section{3. Визуализация наполнения лидерно-стримерной „паутины“}

B следующей серии экспериментов видеокамеру Sony FDR-AX700, 500 fps оснастили фильтром с полосой пропускания 400-500 nm. Разряд был выполнен на схожих начальных условиях с видео № CO127.MP4. У разряда в видео № CO114.MP4 коммутация разряда происходила при напряжении на конденсаторной батарее $5.50 \mathrm{kV}$, а при $2.26 \mathrm{kV}$ разряд прерывался (рис. 4). Одновременно в эксперименте проводили диагностику электрического поля образующихся плазмоидов, поэтому на кадрах 40 


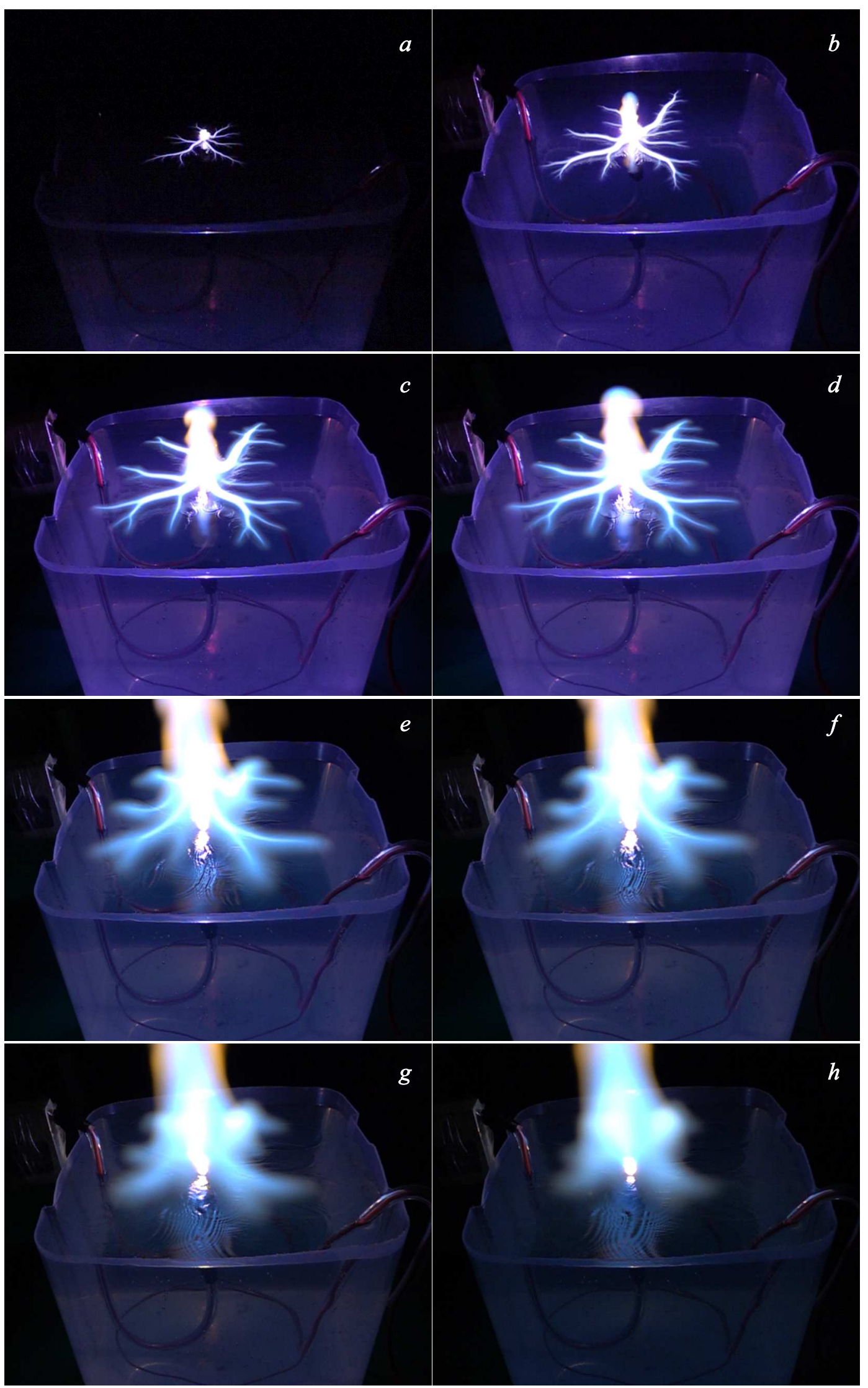

Рис. 3. Эволюция лидерно-стримерной системы, где кадры из видеосъемки соответствуют $2(a), 4(b), 12(c), 18(d), 44(e), 54(f)$, $66(g), 78 \mathrm{~ms}(h)$ разряда. 


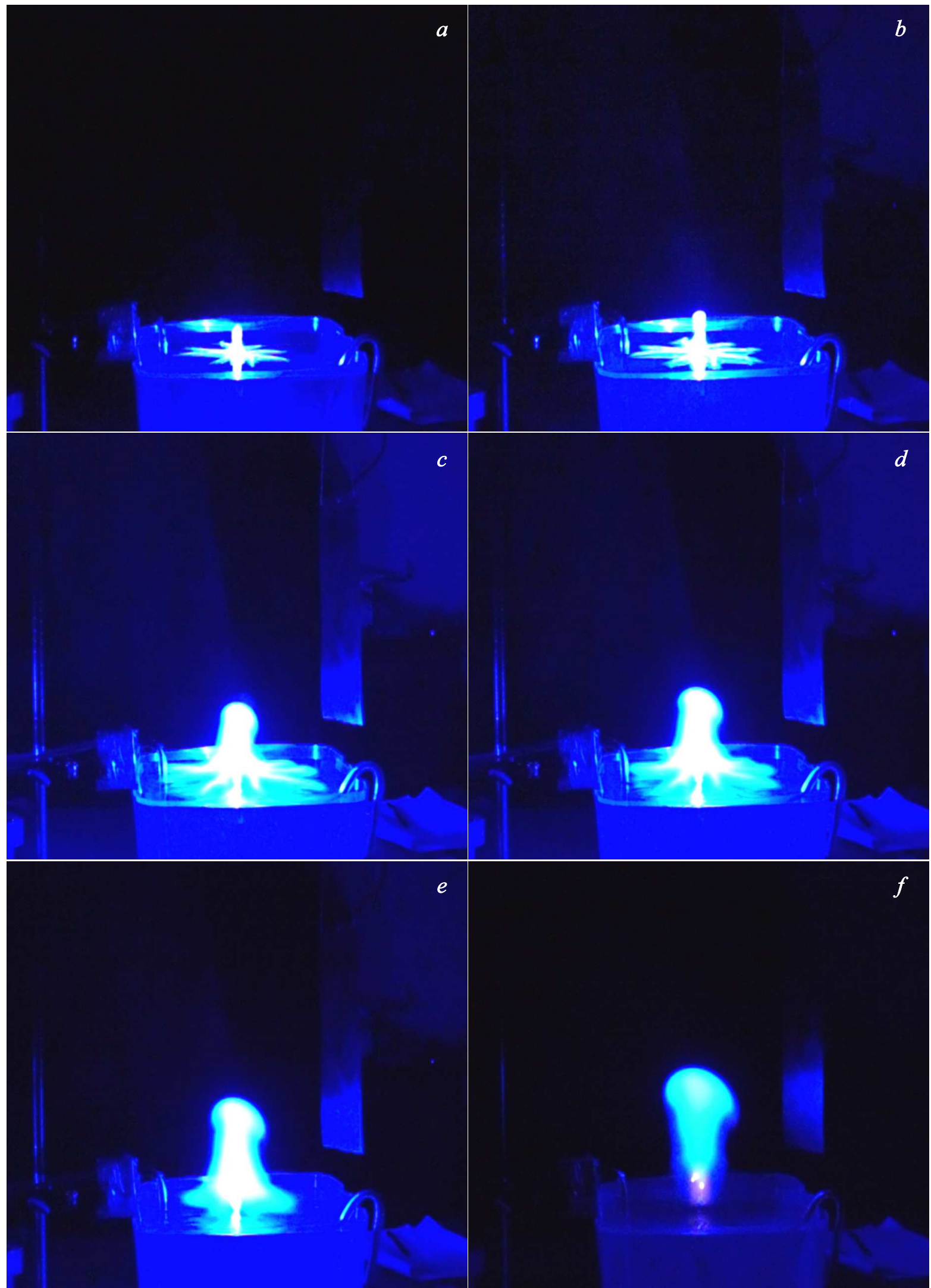

Рис. 4. Видеосъемка с фильтром, полоса пропускания которого 400-500 nm, где выбраны кадры из видео: $2(a), 4(b), 40(c)$, $56(d), 78(e), 120(f), 150(g), 160(h), 176(i), 186 \mathrm{~ms}(j)$. 


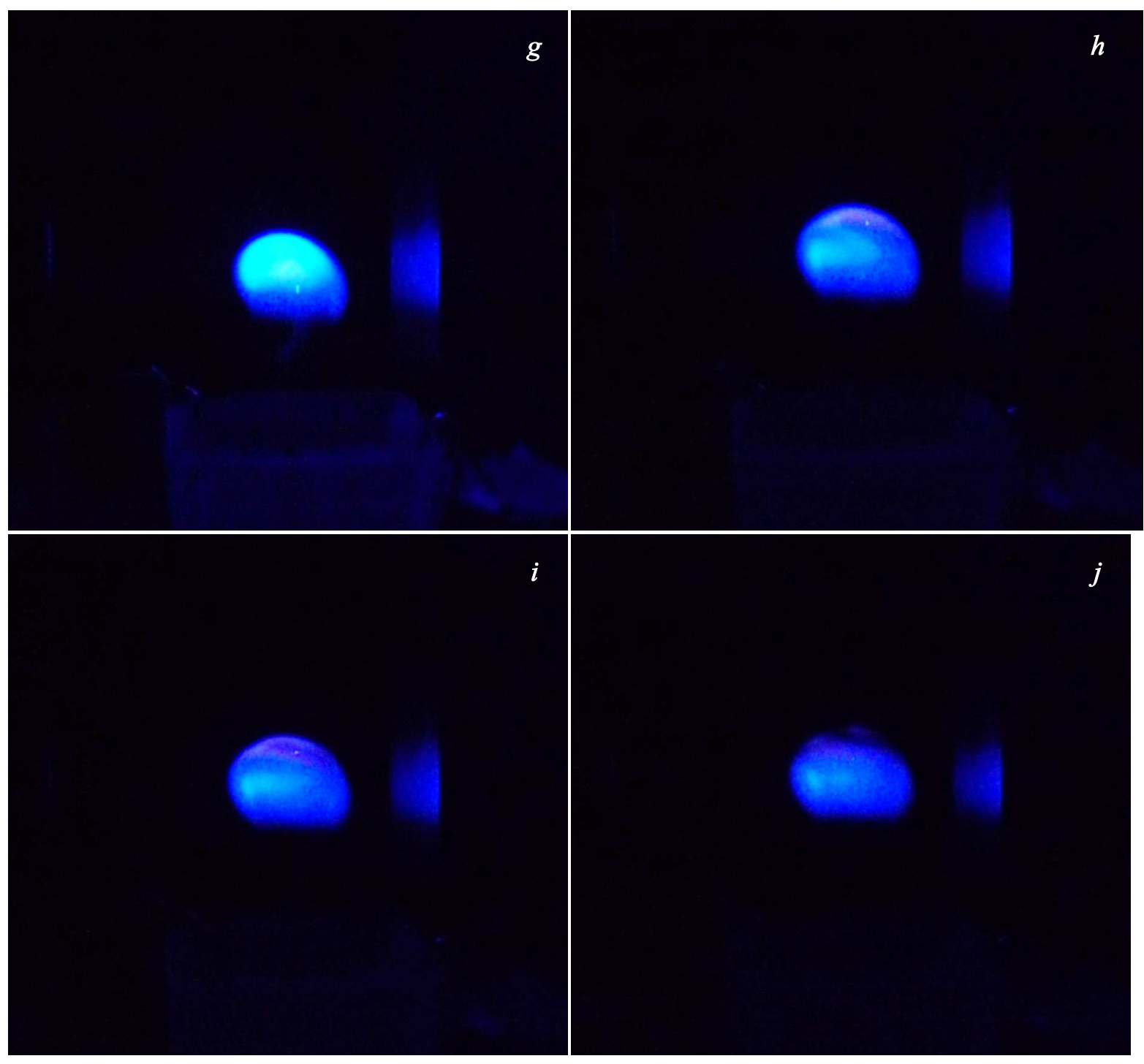

Рис. 4 (продолжение).

(рис. 4,c), $56 \mathrm{~ms}$ (рис. 4, $d$ ) и других видно, что плазмоид поднимается вдоль отражающей полосы и в этой полосе зеркально отражается плазмоид. Эта нержавеющая полоса (часть схемы) имеет размеры $100 \times 300 \mathrm{~mm}$, толщиной $\neq 0.2 \mathrm{~mm}$.

Выше мы отметили, что разряды (рис. 3 и 4) по заданному исходному напряжению одинаковы, конечные напряжения также близки. Но на рис. 4, $a-d$ мы видим разряд, существенно отличающийся от разряда на рис. 3 , $a-d$. На рис. 4 в этом оптическом диапазоне длин волн лидерно-стримерная система практически не видна, вместо нее мы видим почти сплошную структуру.

Структура на рис. 4 трехцветная, сверху синий цвет (больше похожий на ореол), под ним цвет становится похожим на цвет морской волны и далее, под ними, белый цвет. Это говорит о том, что над лидерностримерной паутиной образуется что-то похожее на „шубу“ которая укрывает эту паутину собой. Начиная с рис. $4, f$ видно, что разряд практически отделился от воды и электрода, а это означает, что плазмоид перешел в автономное существование. При этом „шуба“ в этом диапазоне длин волн, на кадрах (рис. $4, g-j$ ) оказывается однородным шарообразным плазмоидом с какимто наполнением цвета морской волны. Когда плазмоид снимают без фильтра (рис. 2), он видится практически однородным в белом свете. В работе [2] показано, что плазмоид имеет оболочку и поэтому наблюдаемая нами эволюция „шубы“ является процессом образования оболочки. Эксперименты по выявлению и определению некоторых свойств оболочки настолько разнообразны, что говорить об ее отсутствии было бы сокрытием истины. В [2] на основании цитируемых в этой работе источников предполагается образование оболочки из нитевидных фрагментов, химические элементы для которых „нарабатываются“ в процессе первой стадии разряда в основном из воздуха (H, N, O, C, Ar и т.д.). Специ- 


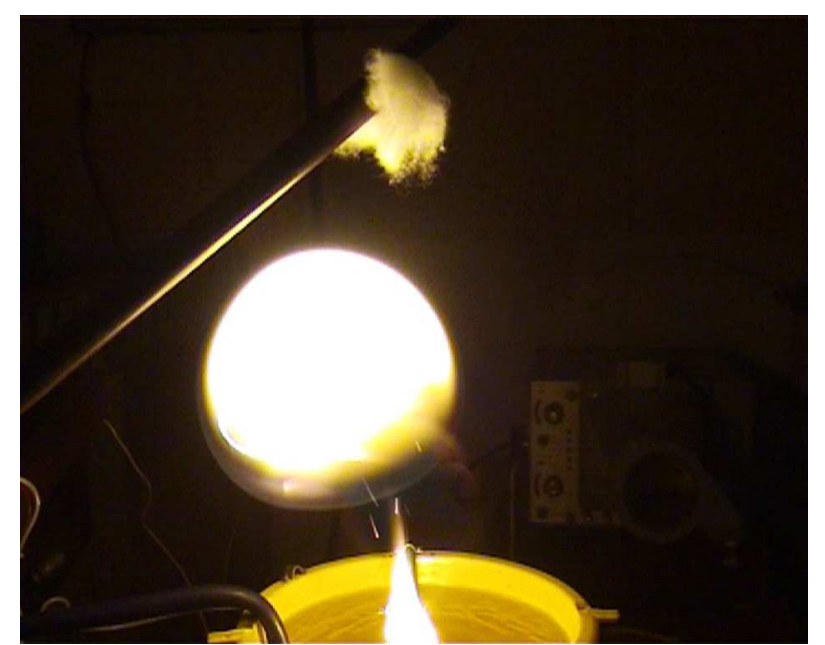

Рис. 5. Визуализированная оболочка плазмоида. Внутри оболочки светящаяся (вверху) и несветящаяся (внизу) области.

альных исследований по вопросу процесса разрушения оболочки не проводилось, предполагаем, что в конце „жизни“ плазмоида она просто окислятся кислородом воздуха, сгорает.

Проанализируем изображения кадров с $120 \mathrm{~ms}$ (рис. 4,f) и далее. Видно, что интенсивность свечения наполнения цвета морской волны снижается. На фотографиях (рис. $4, g-j$ ) это наполнение постепенно теряет способность к свечению в этом диапазоне длин волн. Это наполнение имеет вначале шарообразную форму со срезанной нижней частью, потом пропадает и верхняя часть шара, оно начинает видеться как тор. При этом в синем цвете плазмоид сохраняет вид, близкий к шарообразному. Для сравнения на рис. 5 приведен снимок [2, рис. 7] из работы [2], который был ранее опубликован в малодоступных изданиях с 2002 г., где визуализирована оболочка плазмоида и она имеет шарообразную форму. На этом снимке видно, что внутри оболочки находятся светящаяся (вверху) и несветящаяся (внизу) области. Светящаяся область имеет вид шара со срезанной снизу частью.

Выше мы привели вид плазмоида, снятый в белом свете, где оболочка не визуализирована и плазмоид виден как шар со срезанной снизу частью (рис. 2,4). Дополнительно приведем эволюцию этого плазмоида в белом свете на кадрах из видео № 1226 (рис. 6). Время на видео дано от начала коммутации разряда. В белом свете шаровидный плазмоид видится как шар со срезанной снизу частью, далее как тор (рис. $6, d, e$ ), за который его и воспринимают, например в [4]. В действительности, как показано на рис. 4 и 5, плазмоид не является шаром со срезанной снизу частью, позднее переходящий в тор, а имеет в это время замкнутую шарообразную форму.

То есть в диапазоне длин волн 400-500 nm плазмоид в автономном режиме показал более длительное время существования в виде шарообразной формы, чем на- блюдается в белом свете. Таким образом, сравнивая одновременные изображения на кадрах с использованием узкополосных светофильтров со спектрами плазмоида, полученными в тот же момент времени, можно получить дополнительную информацию. А именно можно точнее определить природу и место в плазмоиде процессов, ответственных за свечение плазмоида. Использование спектрометрических методов диагностики плазмы показало себя с самой лучшей стороны. Так, по величине уширения спектральных линий были выполнены оценки температуры и концентрации электронов в первой фазе разряда, например в [13]. Измерение спектра излучения плазмоида во времени показывает, какие атомы (молекулы) обеспечивают высвечивание на различных стадиях развития плазмоида. Интересным является тот факт, что в спектре плазмоида присутствуют линии, которые четко прослеживаются на протяжении многих сотен ms. Например, в [14] приведен спектр на $290 \mathrm{~ms}$ разряда. При совмещении спектрометрических измерений со скоростной видеосъемкой, в которой одновременно используется несколько камер с различными светофильтрами, позволит идентифицировать области излучения в конкретном диапазоне длин волн на плазмоиде. Что, в конечном счете, должно помочь ответить на вопрос каким образом запасается энергия в плазмоиде: за счет возбуждения долгоживущих состояний атомов, молекул, радикалов или иным способом - за счет высокого электрического потенциала оболочки плазмоида [2].

Очевидно, что в гатчинском разряде электролюминесценция (один из видов люминесценции) является способом создания и возбуждения атомов, молекул, радикалов, например $\mathrm{H}, \mathrm{O}, \mathrm{OH}$, и разнообразных металлических атомов, попадающих в плазмоид из воды и от электрода. Свечение в фиолетовой и ультрафиолетовой части спектра обеспечивает наблюдение с использованием фильтров оболочки у плазмоидов (рис. 4 и 5). Согласно [2] плазмоид имеет значительный нескомпенсированный заряд, который создает корону, в которой электролюминесценция продолжает играть свою роль. Возможно, что запасенная энергия в электрическом поле плазмоида является основным фактором для длительной хемилюминесценции, не исключая в этом процессе роли возбужденных атомов, молекул, радикалов и т.д., попавших в объем плазмоида в первой фазе разряда.

Исходя из работы [2], плазмоид имеет структуру, в которой большую роль играет его „оболочка“ которая препятствует смешиванию содержимого плазмоида с окружающей его атмосферой, например, коллоидного графита, содержавшегося в плазмоиде (рис. 2, b). Исходя из вида неоднородной лидерно-стримерной системы, на рис. 3 трудно предположить наличие такой сплошной, непроницаемой оболочки. Однако в диапазоне 400-500 nm видимого спектра вместо неоднородной лидерно-стримерной системы мы наблюдаем однородное свечение по всей поверхности поднимающегося над водой плазмоида. Это показывает, что вместе с развитием лидерно-стримерной „паутины“ по поверхности 
$a$

$b$
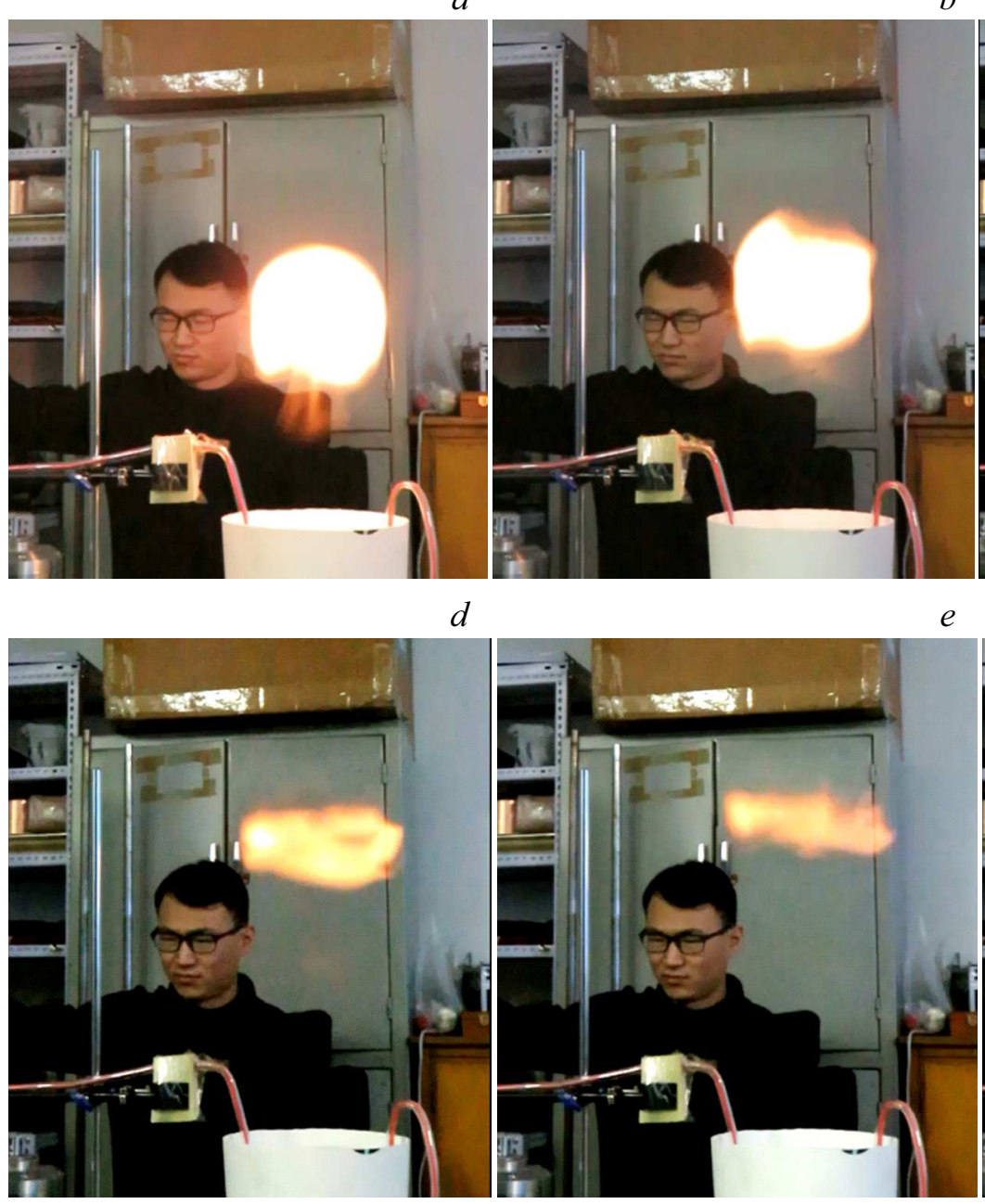

$d$

e
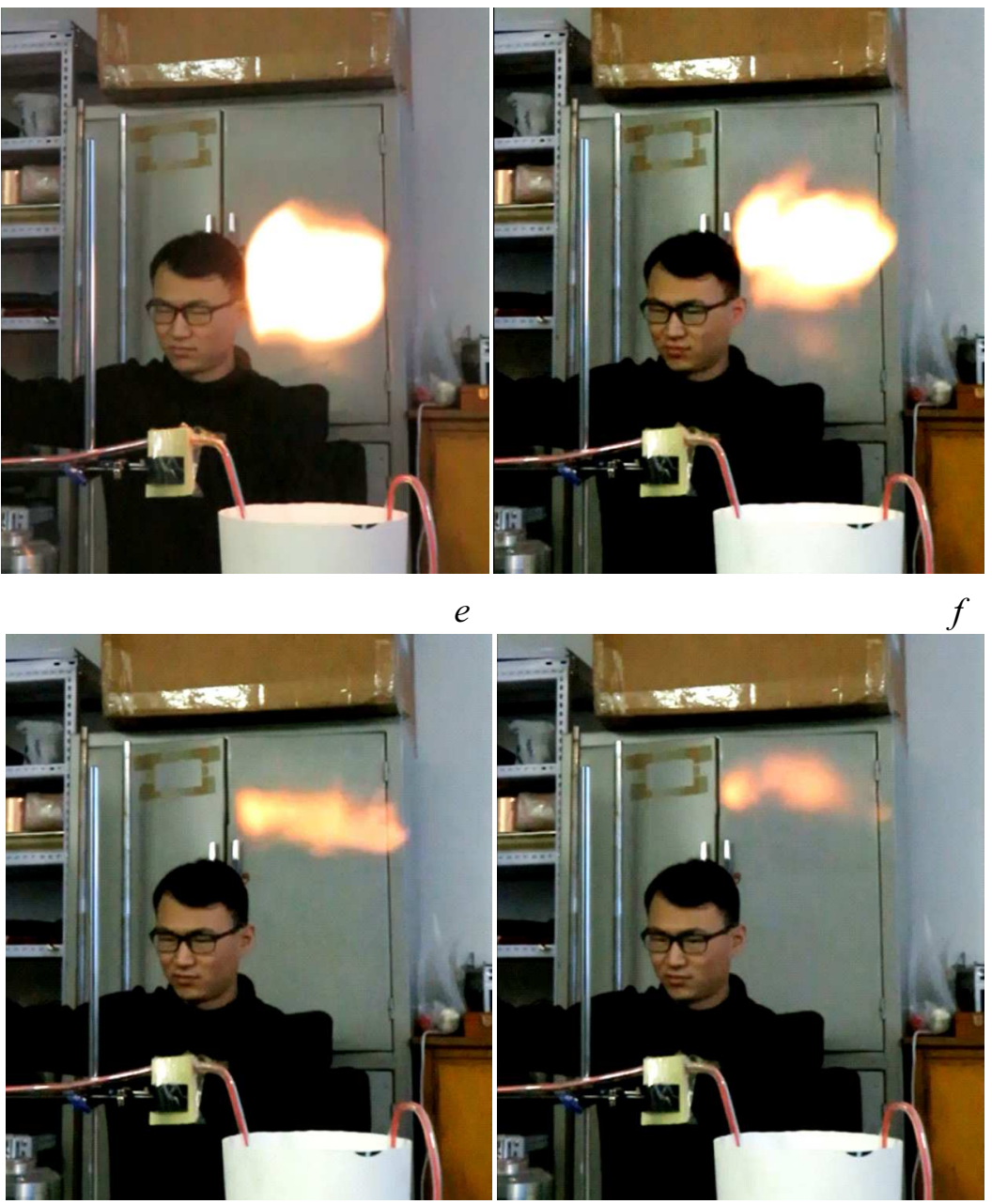

Рис. 6. Видеосъемка при нормальном освещении, где кадры соответствуют $200(a), 233(b), 266(c), 300(d), 333(e), 366$ ms $(f)$.

воды непрерывно идет образование сплошной структуры („оболочки“) с достаточно большим поверхностным натяжением, которая удерживает нескомпенсированный электрический заряд.

\section{4. Наблюдение нового физического эфффекта}

В процессе проведения экспериментов по нахождению режимов съемки, позволяющих получить лучшее разрешение первой фазы гатчинского разряда, зафиксировали следующее: новый физический эффект в гатчинском разряде, записанный в видео № CO157.MP4 снятой камерой Sony FDR-AX700, 1000 fps. Коммутация разряда происходила при напряжении на конденсаторной батареe $5.50 \mathrm{kV}$, а при $2.17 \mathrm{kV}$ разряд прерывался (рис. 7).

Для облегчения коммутации разряда и придания ему перпендикулярной траектории на электрод обычно в гатчинском разряде добавляли $20 \mu 1$ воды [2]. В данном эксперименте добавили большее количество воды на электрод (около 60-80 $\mu 1$ ), что и явилось основной причиной обнаруженного эффекта.

На рис. 7, $b-2 \mathrm{~ms}, 7, c-3 \mathrm{~ms}$ виден светящийся шарик, который похож на шарик, приведенный на рис. 1 из работы [8] и назван авторами этой работы [8] „плазменный шарик“. Изучение образования плазменного шарика с помощью видеокамеры с большей скоростью съемки, как считают авторы [8], позволит лучше понять механизмы, ведущие к образованию плазмоида.

В нашем случае, как видно на рис. 7, светящийся шарик, аналогичный „плазменному“ шарику из работы [8], существовал только первые 3-4 ms (рис. 7, $a-c$ ). После чего в течение нескольких десятков ms светящийся шарик трансформируется в особую структуру, состоящую сначала из ярко светящегося стержня (с 5-8 до 20-40 ms (рис. 7, $d-g$ )), а с $40 \mathrm{~ms}$ (рис. 7,h) уже начинает формироваться ярко светящееся ядро с выходящим из него цилиндром белого цвета. В свою очередь, из цилиндра истекает струя, имеющая меньшую, чем у цилиндра интенсивность свечения. На первом этапе развития разряда в момент существования ярко светя- 


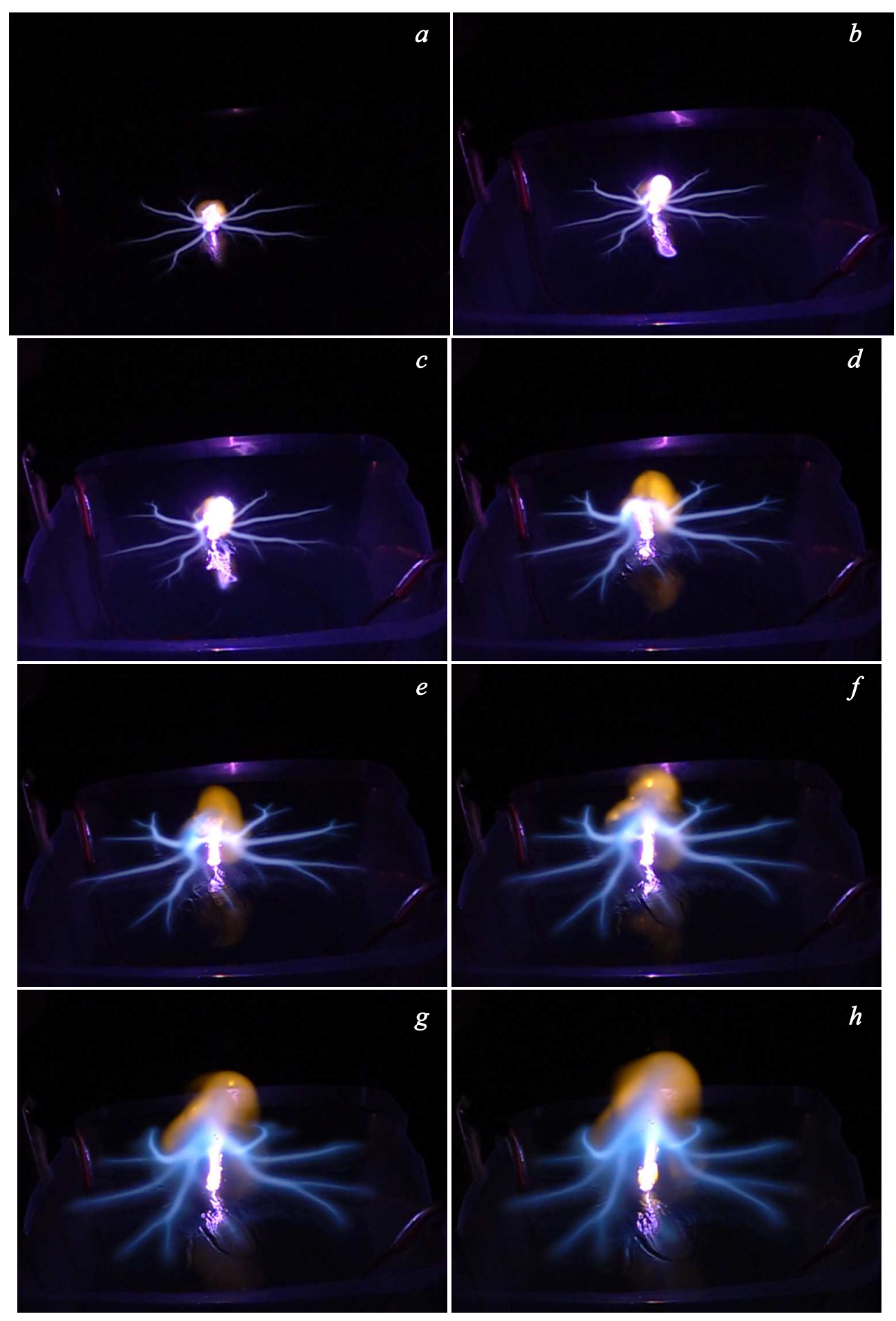

Рис. 7. Эволюция приэлектродного плазменного образования, где кадры видеосъемки: $1(a), 2(b), 3(c), 8(d), 11(e), 20(f)$, $31(g), 40(h), 50(i), 60(j), 70(k), 74(l), 75(m), 78(n), 81(o), 85(p), 89(q), 102 \mathrm{~ms}(r)$.

щегося стержня, например, рис. 7,e,f, лидеры исходят из стержня, образуя своеобразный светящийся крест высотой до $3 \mathrm{~cm}$ над электродом. Помимо этих изменений в разряде происходит эволюция сферы, которая все больше напоминает „шапочку“ (рис. $7, g-j)$, а начиная с $40 \mathrm{~ms}$ (рис. $7, h)$ лидеры прорастают непосредственно из пространства под шапочкой. Шапочка окрашена в бурый цвет благодаря наличию диоксида азота $\left(\mathrm{NO}_{2}\right)$ [2]. Ярко светящееся ядро имеет диаметр около $1.5 \mathrm{~cm}$. Из верхней его части выходит маленький цилиндр до высоты $3 \mathrm{~cm}$ над электродом (рис. 7,k). А лидеры к этому времени поднялись на высоту $5-6 \mathrm{~cm}$. В районе 


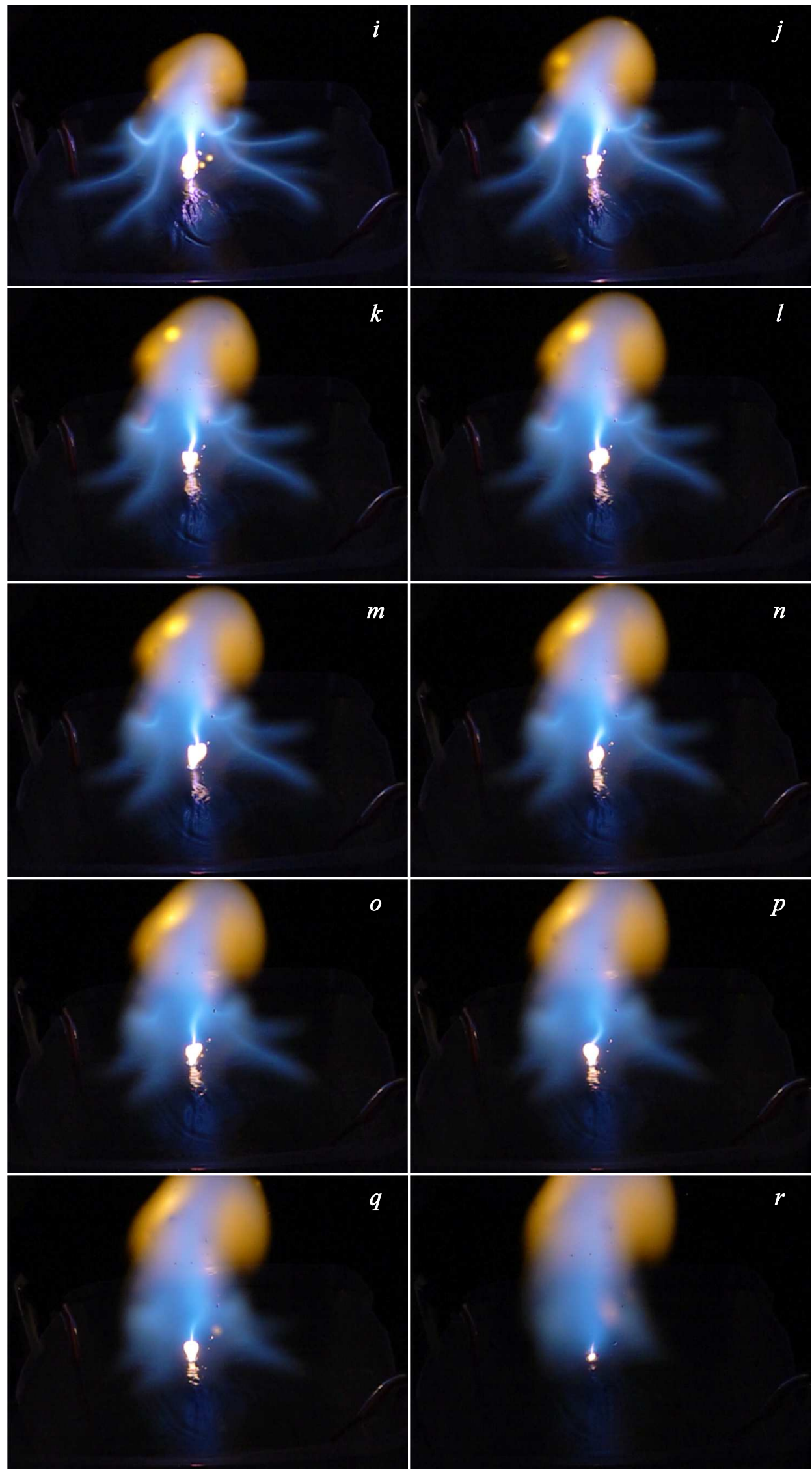

Рис. 7 (продолжение). 
40-50 ms (рис. 7, $h-j$ ) высота цилиндра уменьшилась до $\approx 3 \mathrm{~cm}$ над электродом. Оранжево-бурая шапочка выросла до диаметра $\approx 6 \mathrm{~cm}$. К $50 \mathrm{~ms}$ (рис. 7,i) более четко оформилось ядро и выходящий из него цилиндр. Из этого цилиндра, достаточно ярко очерченного, бьет струя. С $60 \mathrm{~ms}$ после начала разряда и по $102 \mathrm{~ms}$ ядро, незначительно меняя каждуют̃ s свою форму, поворачивает цилиндр так, что струя из него меняет направление своего движения. Определенной последовательности смены направления струи не наблюдается.

\section{5. Гипотеза о механизме функционирования наблюденного физического эффекта}

Для лучшего понимания динамики гатчинского разряда оценим масштаб времен и мощности процессов, происходящих в гатчинском разряде.

А) О мощности. Вначале развиваемая разрядом мощность достигает $500 \mathrm{~kW}$. Получение больших мощностей, длительностью несколько ns, даже $\mu \mathrm{s}$, не представляет большой сложности. В нашем случае развиваемая мощность разряда в $500 \mathrm{~kW}$ сохраняется в течение десятка $\mathrm{ms}$ и формально мощность каждого наблюдаемого на рис. 7, $c, d$ лидера составляет около $70 \mathrm{~kW}$. В разряде уже на первой $\mathrm{ms}$ (рис. 7,a) образовалась сфера бурого цвета диаметром около $2 \mathrm{~cm}$. Она образовалась в результате электрического взрыва воды, находящейся на электроде. Этот взрыв, который распылил воду, находящуюся на электроде, в смеси с десятками синтезированных за это время различных химических соединений $[5,9,10]$, и вынес все эти составляющие на границу образовавшейся сферы (оболочки [2]).

Б) О времени. На первом кадре (рис. 7,a) мы видим сферу диаметром около $2 \mathrm{~cm}$. Возможно ли построение такой сферы за $1 \mathrm{~ms}$ из синтезированных химических соединений? Рассмотрим масштаб времен. Время элементарной реакции в плазме (ионизация, рекомбинации, образование радикалов и т.д.) составляет $10^{-8} \mathrm{~s}$ и менее, значит, за $1 \mathrm{~ms}$ может пройти $10^{5}$ и более поколений реакций. То есть за 100000 поколений вполне возможно построить данную сферу, обнаруженную в эксперименте.

В) Исходя из представленных выше наблюдений, можно высказать следующую гипотезу. В результате взрывного характера выделения мощности в рассматриваемом нами разряде нескомпенсированный электрический заряд (заряды одного знака) „осел“ на составляющих элементах образовавшейся сферы, рис. 7,a. Эта сфера со свободными электрическими зарядами стала представлять собой потенциальный барьер для зарядов того же знака. В связи с этим электрически заряженный стержень с катода трансформировался в сложную композицию, состоящую из яркого ядра, выходящего из него цилиндра с исходящей из него струей. Эта композиция отделена от катода перемычкой меньшего диаметра, чем само ядро, и еще меньший диаметр имеет цилиндр, выходящий из ядра, что можно видеть, например, на рис. 7,l (74 ms разряда) и других.

Такая композиция может напоминать виртуальный катод. Виртуальный катод -потенциальный барьер между катодом и анодом, который возникает внутри разрядного объема над катодом за счет пространственного заряда, создаваемого потоком заряженных частиц в объеме. Образовавшийся виртуальный катод частично пропускает, частично отражает этот поток. Видимо, в данной конфигурации гатчинского разряда, это приводит не только к образованию яркого ядра, соединенного с катодом, но и цилиндра и истекающей из него струи. Возможно, мы имеем визуализацию этого процесса. Накачка одноименными зарядами пространства под шапочкой приводит к повышению потенциала и созданию в этом части пространства сильного неоднородного электрического поля. В связи с этим, начиная с 40-50 ms, лидеры берут свое начало из этого пространства уже, будучи не связанными лидерным каналом непосредственно ни со струей, ни с ядром.

\section{6. Получение в гатчинском разряде плазмоида с наименьшим диаметром}

В ряде работ были предложены экспериментальные модификации в создании гатчинского разряда и указаны пути его возможного использования (применения). Например, автор [15] считает, что гатчинский разряд может быть весьма перспективным для производства водорода. Для этого он предлагает небольшие изменения в схеме гатчинского разряда, которые позволяет генерировать плазменный виртуальный катод, что позволит увеличить выход водорода или перекиси водорода $\left(\mathrm{H}_{2} \mathrm{O}_{2}\right)$.

Интересны эксперименты авторов [16], которые изменили традиционную схему гатчинского разряда, применив обратную полярность электродов, т. е. центральный электрод стал служить анодом, а не катодом. В результате их работы появился ряд вопросов. Мы считаем, что эксперименты по определению минимального напряжения на электроде в [16], для самой возможности появления шарового плазмоида, необходимо уточнить, так как мы получили иные результаты. Нам удалось получить плазмоиды со значительно меньшего начального напряжения, чем в [16].

Из-за малого размера наш „минимальный“ плазмоид имеет малую светимость и поэтому не видны детали установки. Для примера приведем эксперимент, где хорошо видна электродная система (рис. 8), выполненный в аналогичных условиях за исключением начального напряжения. Это видео № C0084.MP4, снятое камерой Sony FDR-AX700, 500 fps.

Приведем кадры из видео № C0089.MP4, снятые камерой Sony FDR-AX700, 500 fps. C целью лучше представить результаты эксперимента один из кадров 


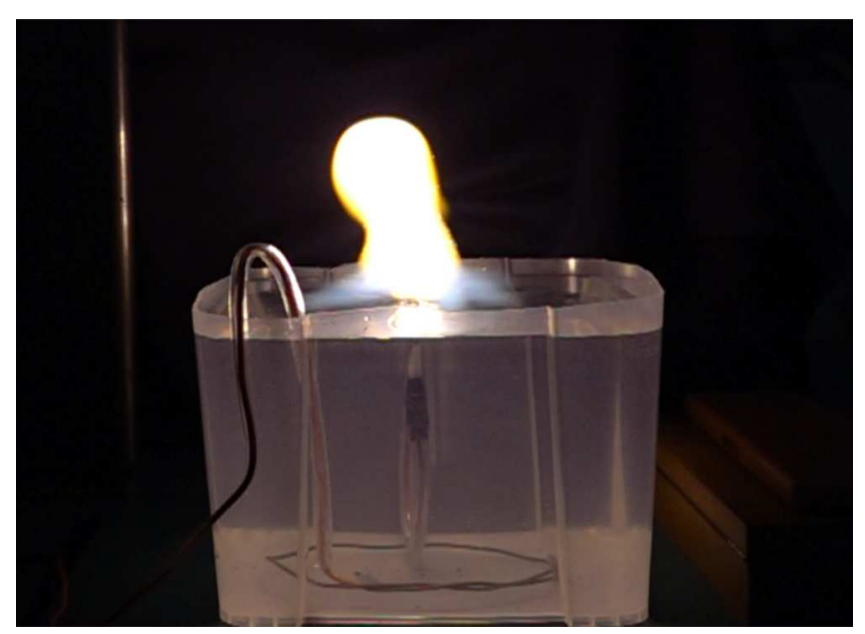

Рис. 8. Вид плазмоида при меньшем начальном напряжении.

видео № C0089.MP4 (рис. 9), где получен рекордно миниатюрный плазмоид, кадр $36 \mathrm{~ms}$ (рис. 9, $h$ ) выполнен с большим увеличением. Коммутация разряда происходила при напряжении на конденсаторной батарее $2.40 \mathrm{kV}$, а при $2.20 \mathrm{kV}$ разряд прерывался. Плазмоид имеет наибольший диаметр 15-17 mm со временем свечения от зарождения до угасания почти $90 \mathrm{~ms}$ (рис. 9).

На кадрах рис. 9 образовавшийся плазмоид висит над электродом и по отражению в воде видно, что он изолирован от катода. Если сравнивать это видео с видео на рис. 8 из [16], отметим, что в [16] наблюдаются „стримеры“ (по терминологии из [16]), а собственно сам плазмоид отсутствует, хоть там разряд осуществляется с достаточно большого напряжения $3500 \mathrm{~V}$, в сравнении с $2400 \mathrm{~V}$ на нашем видео. Разряд, инициирование которого происходило с $2500 \mathrm{~V}$ на рис. 9 из [16], как отмечают авторы, не имеет ни стимеров, ни струи, только искрение. Такая поразительная разница в попытке воспроизвести плазмоид в [16] и в настоящей работе, видимо, связана с инверсией полярности электродов. Интересно сравнение исследования [6] с работой [16]. В [6] отмечается, что, сравнивая некоторые сообщения о шаровой молнии с водно-плазмоидным разрядом, можно найти большое сходство в их описании. Авторы [6] большое внимание уделяют функционированию катодного пятна, которое, как они считают, отвечает за образование основного плазмоида (и мы поддерживаем это утверждение), с обязательным покрытием центрального катода (водой), которое имеет решающее значение для рождения плазмоида. Однако в [16] утверждается, что покрытие катода водой не является необходимой процедурой для производства плазмоидов.

Полученные нами результаты показывают, что в механизме образования плазмоида еще много не решенных вопросов, которые требуют дальнейшего изучения.

\section{7. Послесвечение воздуха при нормальном атмосферном давлении при различных способах введения в него энергии}

Настоящий раздел со ссылками [17-26] не может охватить все вопросы, связанные с послесвечением. Наиболее полно анализ различных механизмов послесвечения плазмоидов выполнен в недавнем обзоре [24]. Следуя этой работе, отметим наиболее важные для нас.

Три четверти века назад при коммутации в электрических сетях (токи 100-300 А и $10000 \mathrm{~V}$ ) наблюдалось длительное до $1 \mathrm{~s}$ послесвечение воздуха после прерывания тока [17]. Автор предположил, что задержка „гашения“ дуги связана с формированием заряженной среды, содержащей электроны, ионы, с возбужденными атомами и молекулами воздуха. В работе приводится фотография светящегося облака размером несколько десятков сантиметров - метр. В следующей работе [18] тот же автор заметил, что при некоторых параметрах тока светящееся облако размером около метра существует 0.1-0.3 s. Автор [18] также отметил „некоторое сходство“ с наблюдаемыми шаровыми молниями и привел видео „рваного“ облака, длительность свечения которого около $250 \mathrm{~ms}$. Отметим, что в год выхода этой статьи (1944), существовало довольно распространенное мнение, что поражение сетчатки глаза светом линейной молнии (в результате чего человек некоторое время „видит“ светящееся пятно) и есть шаровая молния. Даже Никола Тесла сначала придерживался этой точки зрения. Поэтому гипотеза автора [18] о шаровой молнии связана, по нашему мнению, с весьма ограниченными в те годы представлениями об этом редко наблюдаемом объекте.

В работах $[19,20]$ уже целенаправленно были выполнены попытки моделировать шаровую молнию. Энергию вводили в воздух с использованием источника питания $30 \mathrm{~kW}, 75 \mathrm{MHz}$. В [19] представлены 2 фотографии свечения воздуха с расплывчатыми границами, а в [20] приведена только одна фотография (рис. 4) и она совпала с рис. 7 из [19], а вторая фотография (рис. 6 из [19]), в которой свечение неровное и похоже на цилиндр, а не на шаровую молнию, не приведена. В работах $[19,20]$ также отмечалось, что в основном за свечение наблюдаемых плазмоидов ответственны азот и кислород с послесвечением до $1 \mathrm{~s}$.

В статье [21] для проверки гипотезы существования шаровой молнии при постоянном подводе энергии использовали источник энергии $2.45 \mathrm{GHz}$ мощностью $5 \mathrm{~kW}$ (максимальная энергия) микроволнового диапазона. Авторы приводят один случай прожога установки, когда свечение сохранялось 1-2 s после отключения питания.

В [22] был описан эксперимент, в котором использовался индукционный накопитель энергии с запасаемой электрической энергией $500 \mathrm{~kJ}$, что является одним из 


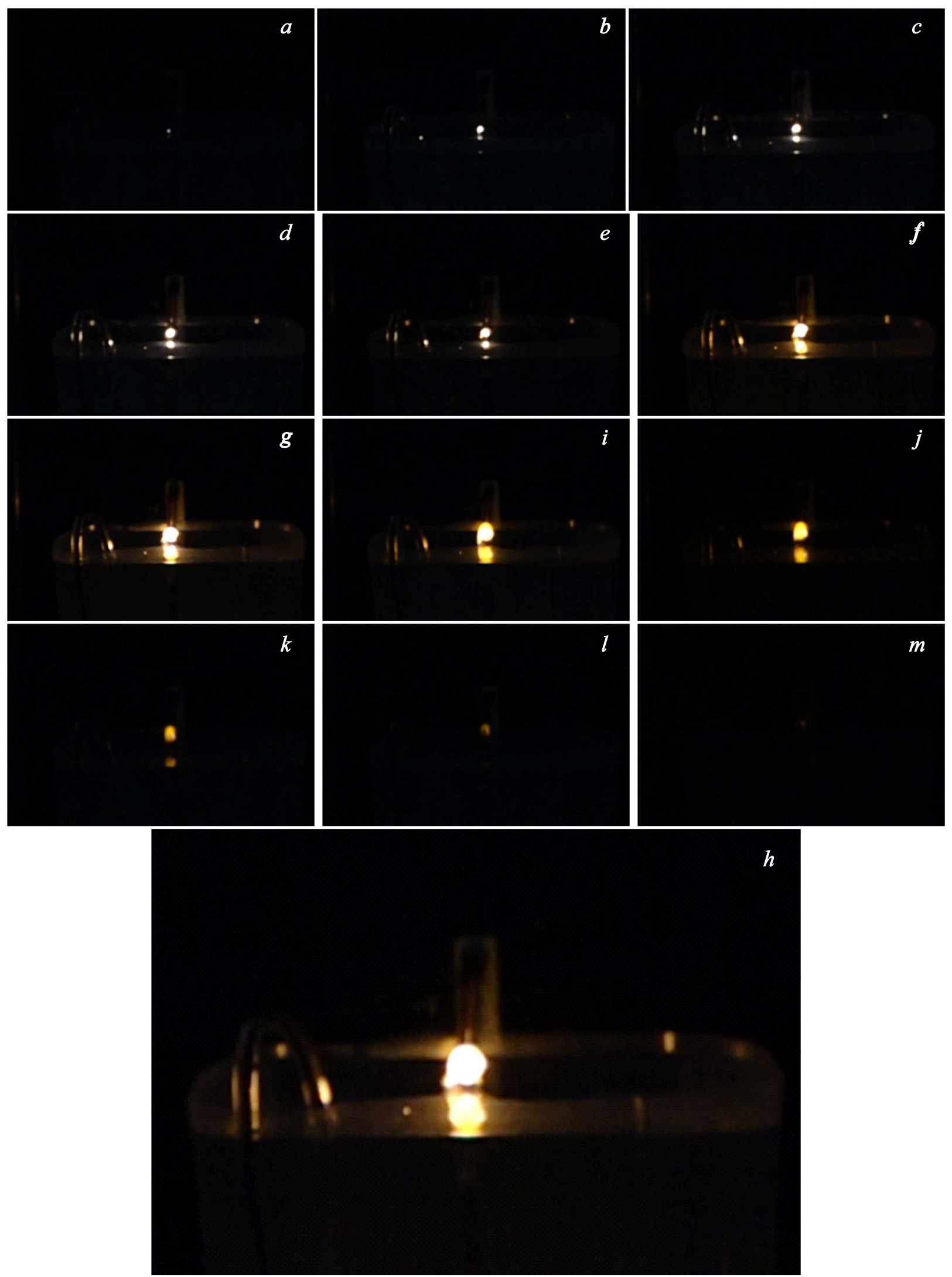

Рис. 9. Динамика развития миниатюрного плазмоида, где кадры видеосъемки: $2(a), 6(b), 14(c), 16(d), 18(e), 28(f), 32(g)$, $36(h), 46(i), 50(j), 58(k), 68(l), 80 \mathrm{~ms}(m)$. 
рекордных показателей для установок, которые создаются для лабораторного получения шаровой молнии. Из текста статьи следует, что 90\% плазменных образований имеют свечение от начала коммутации до окончания свечения около $200 \mathrm{~ms}$. При этом также отмечено, что „... если загородить область над „плазменной пушкой“ до высоты около метра непрозрачным экраном, то из-за экрана появляется ослепительный шар диаметром $30-35 \mathrm{~cm}$. Этот шар гладкий, совершенно непрозрачный и кажется жидким, а не газообразным“. Наши наблюдения плазмоидов „из-за экрана“ показывают, что при наблюдении ослепительного шара, за $0.1 \mathrm{~s}$ после окончания разряда он может казаться гладким, непрозрачным, жидким и любым другим. Также дискуссионным является указанное в свойствах плазменных образований время их жизни „около $2 \mathrm{~s}^{\text {“ }}$ (см. таблицу в [22]). При внимательном прочтении оказывается, что в $10 \%$ случаев, после того как подвод электрической энергии к плазменному образованию прекращается, свечение длится около $100 \mathrm{~ms}$, затем следует пауза в свечении продолжительностью $1100-1200 \mathrm{~ms}$ после чего „... „жизнь“ аналога шаровой молнии заканчивается всплеском светимости“ продолжительностью около $200 \mathrm{~ms}$. При таком нетривиальном поведении светимости вывод [22], что время жизни плазменного образования „около $2 \mathrm{~s}^{\text {“ }}$ вызывает сомнение.

Большой и насыщенной экспериментами по изучению гатчинского разряда является только что вышедшая работа [23]. В ней приводится интересный факт, что плазмоиды в инфракрасном диапазоне живут более $1.5 \mathrm{~s}$, а объемная плотность энергии около $\mathrm{MJ} / \mathrm{m}^{3}$. В [23] на основании полученных экспериментальных данных утверждается, что в гатчинских плазмоидах радикал $\mathrm{OH}$ $\left(\mathrm{A}^{2} \Sigma \rightarrow \mathrm{X}^{2} \Pi\right)$ является наиболее заметной спектральной составляющей эмиссии на порядки интенсивнее любого другого компонента и только в конце жизни автономного плазмоида преобладающей становится эмиссия от натрия. Внешний вид плазмоида определяется не тепловым излучением, а в основном неравновесным свечением элементов и радикалов $\mathrm{H}, \mathrm{O}, \mathrm{OH}$, что коррелирует с обсуждаемой в [24] ролью кислорода. В работе [24] также было выдвинуто предположение о важности метастабильных состояний молекул кислорода для гатчинских плазмоидов. Эмиссионных линий от азота и его соединений не наблюдалось. Поэтому высказанное выше в данной работе предположение, что запасенная энергия в электрическом поле плазмоида является основным его энергетическим резервуаром, не исключая энергетического вклада от возбужденных атомов, молекул, радикалов и т.д., попавших в объем плазмоида в первой фазе разряда, требует дополнительного исследования.

В литературе неоднократно отмечалось, что плазмоиды в гатчинском разряде поразительно похожи на шаровую молнию. Однако вопрос, являются ли они полными аналогами природной шаровой молнии, является до сих пор дискуссионным. Для сравнения свойств шаровой молнии и гатчинских плазмоидов в объемной работе [2] выделен значительный раздел. Фактически он занимает, со ссылками на другие разделы работы [2], половину статьи. Здесь же для сравнения гатчинских плазмоидов с шаровой молнией сопоставим общепринятое свойство для таких объектов - „время жизни“.

В классической работе Дж. Барри [25], цитируемой практически во всех публикациях по шаровой молнии, считается, что „шаровая молния „живет“ $1-2 \mathrm{~s}$ или менее“. Он уточняет, что: „Согласно имеющимся сообщениям, шаровая молния „живет“ чаще всего $1-2 \mathrm{~s}$. Такое или меньшее время жизни отмечалось в 80\% изученных сообщений“. В более поздних публикациях, например [26], создана наблюдательная модель шаровой молнии, параметры которой получены усреднением большого массива данных (средняя наблюдаемая шаровая молния, средняя шаровая молния) [26]. Наблюдательная модель, согласно которой средняя шаровая молния „живет“ около $10 \mathrm{~s}$, представляет большую практическую ценность. Она проста, и с ее помощью можно сопоставить различные предлагаемые гипотезы. Гатчинскому плазмоиду пока еще достаточно далеко даже до средней шаровой молнии. Однако, пусть хотя и медленное, но увеличение в экспериментах среднего времени их жизни вселяет осторожный оптимизм и стимулирует работы в этом направлении.

\section{Выводы}

Основные выводы из проведенного исследования следующие:

Общая картина разряда при скорости съемки до 1000 fps позволяет наблюдать контрастные кадры развития лидерно-стримерной системы и взаимодействие ее с поверхностью воды.

Применение при съемке фильтра с полосой пропускания 400-500 nm позволило выделить и наблюдать в процессе развития лидерно-стримерной системы новый компонент первой фазы гатчинского разряда. Этот компонент, как предполагалось ранее в [2], является создающейся в первой фазе разряда сплошной, непроницаемой оболочкой будущего плазмоида. В этом диапазоне длин волн область пространства вблизи поверхности воды оказалась заполненной более равномерной компонентой, чем можно было бы предположить, основываясь на фрагментарном построении лидерно-стримерной системы на поверхности воды. В этом диапазоне длин волн образующаяся сплошная, непроницаемая оболочка плазмоида скрывает под собой лидерно-стримерную систему, которая под этой оболочкой плохо просматривается и с течением времени оказывается практически ненаблюдаемой.

Далее в диапазоне 400-500 nm длин волн в автономной фазе существования плазмоида оболочка длительное время наблюдается в шарообразной форме, а внутренне наполнение постепенно приобретает вид тора. Съемка 
плазмоида в диапазоне 400-500 nm длин волн показала, что делать выводы о форме и свойствах плазмоида по изображению только в белом свете некорректно. Тем более что переходы даже в белом свете шар - тор и наоборот тор - шар наблюдались в работе [27]. В будущем, при одновременной съемке в нескольких диапазонах длин волн, появится возможность более полно идентифицировать процессы, идущие в гатчинском разряде. Метод съемки процессов (объекта) в нескольких диапазонах длин волн не нов, он, например, применен на Solar Dynamics Observatory, запущенной в космос 11 февраля 2010 г., где съемка Солнца производилась в 10 диапазонах длин волн [28].

В процессе изучения первой фазы разряда при варьировании параметров разряда был открыт новый физический эффект - сложноустроенное плазменное образование, соединенное с катодом. Оно состоит из яркого ядра, соединенного с катодом перемычкой меньшего диаметра, чем само ядро, выходящего из ядра цилиндра с исходящей из него струей. Предположительно, это образование является виртуальным катодом, функционирующим в открытой атмосфере, которое удалось удачно визуализировать. Виртуальный катод частично пропускает, частично отражает поток заряженных частиц. В данной конфигурации гатчинского разряда, это приводит не только к образованию яркого ядра (виртуального катода), соединенного с катодом, но и цилиндра и истекающей из него струи. Визуализирован поток заряженных частиц с катода на виртуальный катод и отраженных от виртуального катода, а также заряженных частиц, частично пропущенных через виртуальный катод по цилиндру. Виртуальный катод предполагает наличие нескомпенсированного электрического заряда в компактной области пространства над катодом. Совместно с данными работы [2], где в плазмоидах гатчинского разряда определен существенный нескомпенсированный заряд, можно утверждать, что роль в плазмоидах нескомпенсированного заряда определяющая.

Получение миниатюрного плазмоида диаметром 15-17 mm (рис. 9) напоминает неоднократно описанное в [29] образование шаровых молний с металлических предметов. Удивительно, что в этом случае в гатчинском разряде не наблюдался процесс образования лидерно-стримерной системы. Возможно, что модификация этого процесса приведет к созданию еще более долгоживущих светящихся образований.

\section{Благодарности}

Авторы благодарят рецензента за ряд ценных замечаний и новую полезную информацию, особенно за указанную рецензентом новую статью [23], во многом дополняющую нашу работу. Отметим также выявленный в [23] интересный факт, что плазмоиды в инфракрасном диапазоне живут более $1.5 \mathrm{~s}$, а объемная плотность энергии около $1 \mathrm{MJ} / \mathrm{m}^{3}$. Разд. 7 настоящей работы инициирован рецензентом, так как приведенные в этом разделе работы [17-24] рекомендованы рецензентом для анализа возможных механизмов по времени послесвечения плазмоидов.

\section{Конфликт интересов}

Авторы заявляют, что у них нет конфликта интересов.

\section{Список литературы}

[1] Г.Д. Шабанов. Письма в ЖТФ, 28 (4), 81 (2002) [G.D. Shabanov. Tech. Phys. Lett., 28 (2), 164 (2002).]

[2] Г.Д. Шабанов. УФН, 189 (1), 95 (2019). [G.D. Shabanov. Physics-Uspekhi, 62 (1), 92 (2019)]. DOI: $10.3367 /$ UFNe.2018.03.038318

[3] N. Hayashi, H. Satomi, T. Mohri, T. Kajiwara, T. Tanabe. IEEJ Transactions on Electrical and Electronic Engineering, 4, 674 (2009). DOI: $10.1002 /$ tee. 20460

[4] V.L. Bychkov, N.P. Savenkova, S.V. Anpilov, Y.V. Troshchiev. IEEE Trans. Plasma Sci., Vol. 40, (12), P. 1, 3158 (2012).

[5] D.M. Friday, P.B. Broughton, T.A. Lee, G.A. Schutz, J.N. Betz, C.M. Lindsay. J. Phys. Chem. A, 117 (39), 9931 (2013). http://dx.doi.org/10.1021/jp400001y

[6] K.D. Stephan, S. Dumas, L. Komala-Noor, J. McMinn. Plasma Sources Sci. Technol., 22 (2), 025018 (2013). http://stacks.iop.org/0963-0252/22/i=2/a=025018

[7] U. Fantz, S. Kalafat, R. Friedl, S. Briefi. J. Appl. Phys., 114 (4), 043302 (2013). http://dx.doi.org/10.1063/1.4816311

[8] U. Fantz, S. Briefi, R. Friedl, M. Kammerloher, J. Kolbinger, A. Oswald. IEEE Trans. Plasma Sci., 42 (10), 2624 (2014).

[9] S.E. Dubowsky, D.M. Friday, K.C. Peters, Z. Zhao, R.H. Perry, B.J. McCall Int. J. Mass Spectrom., 376, 39 (2015).

[10] S.E. Dubowsky. Characterization and analysis of ball plasmoid discharges. DISSERTATION: Submitted in partial fulliment of the requirements for the degree of Doctor of Philosophy in Chemistry in the Graduate College of the University of Illinois at Urbana-Champaign, 2018. Urbana, Illinois. Doctoral Committee: Prof. B.J. McCall, Chair; Prof. D.D. Dlott, Prof. J.G. Eden, Prof. D.N. Ruzic.

[11] Э.М. Базелян, Ю.П. Райзер. УФН, 170 (7), 753 (2000). [E.M. Bazelyan, Yu.P. Raizer. Phys. Usp., 43 701, (2000).]

[12] E.M. Bazelyan, Yu.P. Raizer. Lightning Physics and Lightning Protection (Bristol: Institute of Physics Publ., 2000). [Пер. с англ. Базелян Э.М., Райзер Ю.П. Физика молнии и молниезащиты (Физматлит, М., 2001)]

[13] A. Versteegh, K. Behringer, U. Fantz, G. Fussmann, B.J. Uttner, S. Noack. Plasma Sources Sci. Technol., 17, 024014 (2008). DOI: 10.1088/0963-0252/17/2/024014

[14] Y. Sakawa, K. Sugiyama, T. Tanabe, R. More. Plasma and Fusion Research: Rapid Commun., 1, 39 (2006).

[15] Fabrice David. Infinite Energy Issue, 145, (2019).

[16] S.E. Dubowsky, A.N. Rose, N.G. Glumac, B.J. McCall. Plasma, 3 92, (2020). DOI:1 0.3390/plasma3030008

[17] J.J. O’Doherty. Nature, 153 (3888), 558 (1944).

[18] J.J. O'Doherty. Nature, 154 (3906), 339 (1944).

[19] J.R. Powell, D. Finkelstein. Adv. Geophys., 13, 141 (1969).

[20] J.R. Powell, D.Finkelstein. Am. Scientist, 58, 262 (1970).

[21] Y.H. Ohtsuki, H. Ofurutont. Nature, 350, 139 (1991). 
[22] В.Н. Кунин, В.С. Плешивцев, Л.В. Фуров. ТВТ, 35, 866 (1997).

[23] R. Friedl, U. Fantz, I. Pilottek, D. Schmid, S. Steibel. Phys. D: Appl. Phys., 54095205 (2021). https://doi.org/10.1088/13616463/abc918

[24] M.L. Shmatov, K.D. Stephan. J. Atmospheric and SolarTerrestrial Phys., 195, 105115 (2019).

[25] Дж. Барри. Шаровая молния и четочная молния (Мир, M., 1983). [J.D. Barry Ball Lightning and Bead Lightning (Plenum, NY., 1980)]

[26] Б.М. Смирнов. УФН, 160 (4), 1 (1990).

[27] D.Ch. Kim, A.S. Semenov, V.A. Efimov, Yu.V. Bebikhov. 2020 International Multi-Conference on Industrial Engineering and Modern Technologies (FarEastCon) 2020978-1-7281-69514/20/@ IEEE (2020).

[28] Электронный ресурс. Режим доступа: https://sdo.gsfc.nasa.gov/

[29] И.П. Стаханов. О физической природе шаровой молнии (Мир, М., 1996), 3-е изд. 